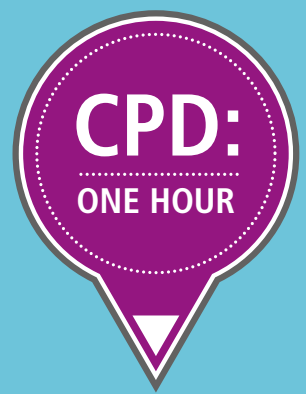

\title{
and

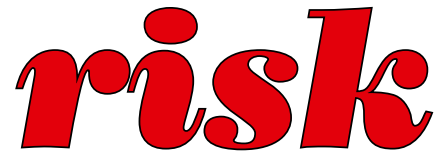

- the three words at the heart of the decision whether a hygienist/therapist is assisted by a dental nurse

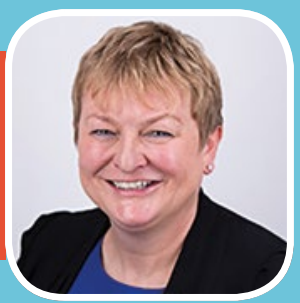

\section{Dentolegal consultant Sue Boynton provides her} take on one of dentistry's most topical issues.

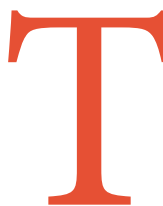

he recent article in $B D J$ In Practice 'Can a hygienist work without a nurse?'1 has generated discussion amongst the profession. An important

point to emerge is that the individual hygienist/therapist is responsible for assessing and managing the risk of working without a colleague. If anything goes wrong, the buck stops with you, not the owner of the practice you are working in.

The skills of assessing and managing risk are essential. This article sets out the considerations which should be included in any risk assessment. They are:

- Regulatory requirements

- Patient safety

- Personal safety.

\section{Regulatory requirements}

The GDC sets high-level principles and registrants are expected to use their professional judgement in making their decision and be able to justify it. The GDC guidance Standards for the Dental Team ${ }^{2}$ does not discriminate between different registrant groups, so there is nothing specific to hygienists.

In the guidance 'must' is used where the duty is compulsory. In the following excerpts the
GDC's use of must and should are in bold by way of emphasis.

- 6.2 You must be appropriately supported when treating patients

- 6.2.1 You must not provide treatment if you feel that the circumstances make it unsafe for patients.

Meanwhile, 'should' is used where the duty would not apply in all situations and where there are exceptional circumstances outside your control that could affect whether, or how, you can comply with the guidance. Should is also used when we are providing an explanation of how you will meet the overriding duty.

- 6.2.2 You should work with another appropriately trained member of the dental team at all times when treating patients in a dental setting. The only circumstances in which this does not apply are when:

- Treating patients in an out of hours emergency,

- Providing treatment as part of a public health programme, or

- There are exceptional circumstances.

'Exceptional circumstances' are unavoidable circumstances which are not routine and could not have been foreseen. Absences due to leave or training are not exceptional circumstances.

- 6.2.3 If there are exceptional circumstances which mean you cannot work with an appropriately trained member of the dental team when treating a patient in a dental setting, you must assess the possible risk to the patient of continuing treatment.

Aspects of this guidance require careful consideration; that is where the GDC expects registrants to use their professional judgement. By way of assistance, it is helpful that as a frequently asked question (FAQ) in the online standards ${ }^{3}$ the GDC includes:

'I am a dental hygienist; do I have to work with a dental nurse at all times?'

The GDC's answer includes:

'It is not acceptable for dental professionals to be working alone on the premises when they are treating patients. Ideally, we would want all members of the dental team to have another member of the dental team with them in the same room, when they are treating patients.

However, if in their professional judgement, they decide that having another member of the dental team on the premises who is able to offer them support if needed, complies with the requirement to 'work with' an appropriately trained team member and does not put patients 
at risk, and they therefore choose to work under this arrangement, they must be able to justify their decision.

When making a professional judgement, the requirements of other regulators should also be taken into account. Whilst the CQC only regulates practices in England it might be helpful to take a look at the CQC's view.

The CQC identifies two aspects of lone working: ${ }^{4}$

- Having someone else on the premises so there is support in a medical emergency and,

- Whether you need chairside support from a dental nurse when treating patients.

In making a judgement on whether or not lone working is safe the CQC considers not only the GDC Standards for the Dental Team, but also the Health and Social Care Act 2008 (Regulated Activities) Regulations 2014, ${ }^{5}$ regulation 18 (staffing), and regulation 12 (safe care and treatment).

On the issue of treating patients alone without chairside support from a dental nurse the CQC states:

'If our inspectors found a dental care professional to be working alone without chairside support from a dental nurse, we would expect to see that a risk assessment had taken place. This needs to take into account how support or assistance would be provided in a medical emergency; for either the patient or dental care professional. This relates to the key line of enquiry S4 in the safe question: "How are risks to individual people who use the services assessed, and their safety monitored and maintained?"

\section{Patient safety}

Patient safety is absolutely paramount in dentistry. Any professional judgement would include not only patient factors and treatment delivery factors, but also the context of treatment delivery, including the location of the surgery in relation to the rest of the team; in a working environment some surgeries may be more physically isolated from the rest of the team than others.

\section{Personal safety}

Whilst there is rightly a focus on patient safety, it is also important to consider the safety of team members. This would include physical safety and the potential exposure to allegations of improper conduct. In addition, situations can arise where a patient makes a dental professional feel uncomfortable.

Consideration might also be given to the reported increased stress and burnout in the dental profession. ${ }^{6}$ Running alongside all of this is the increased litigation in dentistry, particularly in relation to periodontal disease.
In Avoiding the pitfalls of dento-legal issues ${ }^{7}$ Drs R Wadia and L D'Cruz note the increased likelihood of a hygienist being involved in a claim in negligence regarding periodontal disease. Like any aspect of dentistry, the provision of periodontal care is not just about treatment and discussion, maintaining appropriately detailed records is a key aspect. Some dental professionals take a team approach to record keeping, others prefer to carry out that task alone. The quality of the records might depend on the extent to which the dental professional is multitasking, fatigued, or running be a significant issue; crucially that discussion should be entirely separate from a risk assessment.

If ultimately an agreement cannot be reached it makes sense to seek further advice. The indemnity organisations are well placed to provide advice to their individual members. Indeed, many take the view that advice sought at an early stage is invaluable. It also makes sense, as when a dental professional faces a challenge, their indemnity organisation would normally be their first port of call.

\section{'IDEALLY, WE WOULD WANT ALL MEMBERS OF THE}

\section{DENTAL TEAM TO HAVE ANOTHER MEMBER OF THE}

DENTAL TEAM WITH THEM IN THE SAME ROOM, WHEN THEY ARE TREATING PATIENTS. (SOURCE: GDC FAQS)'

late. Indeed, human factors including task overload, fatigue and running late can result in errors which in themselves could lead to patient safety incidents, complaints, claims in negligence or GDC issues.

It is important to note that there are some situations, for example when acting as an operator-sedationist, when the assistance of an appropriately trained person is mandatory.

Using a structure to carry out your risk assessment may prevent relevant aspects being overlooked. What is required is a professional judgement, and the ability to justify the decision made. One might run a number of hypothetical scenarios, for example:

What would happen if:

- The patient had a medical emergency

- The patient became aggressive or abusive

- The patient made the dental professional feel uncomfortable

- The dental professional had a medical emergency.

So far so good, but what happens if the hygienist's risk assessment indicates that a dental nurse is required, and the practice owner's risk assessment indicates the opposite? A discussion to explore both perspectives would be a good start, after all one party may have identified something which the other has not. Setting aside for a moment whether the clinician is a dentist or a hygienist, running each of the above scenarios with and then without a dental nurse is likely to be extremely valuable. A similar exercise could also be run for other relevant issues.

Whilst it is right to say that finances could

\section{References}

1. D'Cruz L, Wadia R. Can a hygienist work without a nurse? BDJ In Practice 2019; 32: 14-15.

2. General Dental Council. Standards. 2013. Available at: https://standards.gdc-uk.org/ pages/principle6/principle6.aspx (accessed February 2019).

3. General Dental Council. FAQs. Available at: https://standards.gdc-uk.org/pages/ principle6/faq.aspx (accessed March 2019).

4. CQC.Dental Mythbusters 13. Lone working in a dental practice setting. Online information available at: https://www. cqc.org.uk/guidance-providers/dentists/ dental-mythbuster-13-lone-working-dentalpractice-setting (accessed February 2019).

5. UK Government. Health and Social Care Act 2008 (Regulated Activities) Regulations 2014. Available at: http://www.legislation.gov. uk/uksi/2014/2936/contents/made (accessed February 2019).

6. Toon M, Collin V, Whitehead P, Reynolds L. An analysis of stress and burnout in UK general dental practitioners: subdimensions and causes. Br Dent J 2019; 226: 125-130.

7. Wadia R, D'Cruz L. Avoiding the pitfalls of dento-legal issues. BDJ Team 2018; 5: DOI: 10.1038/bdjteam.2018.91.

\section{Author bio}

Sue Boynton BDS LLM FFGDP(UK) is an Independent Dentolegal Consultant. 